\title{
Development of Ethnomathematics-Based Teaching Materials for Elementary Students
}

\section{Azamul Fadhly Noor Muhammad, Noer Intan Novitasari}

STKIP Majenang

fadhlee46@gmail.com

\section{Article History}

accepted 24/09/2019

\begin{abstract}
Teaching material is a collection of material and images compiled by the teacher. Learning mathematics in elementary school (SD) really needs to provide content between mathematics in the daily world of students based on local culture with school mathematics. One of the innovative mathematics learning in elementary school can be done by linking the material with culture or ethnomatematics. Ethnomatematics-based teaching materials in elementary schools can be defined as a collection of special elementary materials compiled by teachers in facilitating the process of learning mathematics in class related to culture, either in the form or form that is often encountered by students. The advantages of teaching materials consist of: 1) Study From Anywhere, Anytime; 2) No Commuting; 3) Flexibility to Choose. While the shortcomings of teaching materials consist of: 1) High Chances of Distraction in the Class; 2) No Social Interaction; 3) Takes A Lot of Time and Money. The research method used is the Library Study (Library Research). The data analysis technique used in this study is the Content Analysis method.
\end{abstract}

Keywords: Bahan Ajar, Etnomatematika, Matematika untuk Sekolah Dasar.

\begin{abstract}
Abstrak
Bahan ajar merupakan kumpulan materi dan gambar yang disusun oleh guru. Pembelajaran matematika di sekolah dasar (SD) sangat perlu memberikan muatan antara matematika dalam dunia sehari-hari siswa yang berbasis pada budaya lokal dengan matematika sekolah. Salah satu pembelajaran matematika yang inovatif di SD dapat dilakukan melalui mengaitkan materi dengan budaya atau disebut etnomatematika. Bahan ajar berbasis Etnomatematika di SD bisa didefinisikan sebagai kumpulan materi khusus SD yang disusun oleh guru dalam memudahkan proses pembelajaran matematika di kelas yang berkaitan dengan budaya, baik berupa bentuk atau kebiasaan yang sering ditemui oleh siswa. Kelebihan dari bahan ajar terdiri dari: 1) Study From Anywhere, Anytime; 2) No Commuting; 3) Flexibility to Choose. Sedangkan kekurangan dari bahan ajar terdiri dari: 1) High Chances of Distraction In The Class; 2) No Social Interaction; 3) Takes A Lot of Time And Money. Metode penelitian yang digunakan adalah Studi Kepustakaan (Library Research). Teknik analisis data yang digunakan dalam penelitian ini adalah metode analisis isi (Content Analysis).
\end{abstract}

Kata kunci: Teaching Material, Ethnomathematics, Matematics for Elementary School.

Social, Humanities, and Education Studies (SHEs): Conference Series https://jurnal.uns.ac.id/shes

p-ISSN 2620-9284

e-ISSN 2620-9292 


\section{PENDAHULUAN}

Implikasi diterbitkan Permendikbud No. 57 Tahun 2014 menunjukkan bahwa pengembangan segala aspek kecakapan siswa diperoleh dari berbagai muatan pelajaran. Dalam konteks muatan Matematika, kecakapan matematis merupakan bagian dari kecakapan hidup yang harus dimiliki siswa terutama dalam pengembangan penalaran, komunikasi, dan pemecahan masalah-masalah yang dihadapi dalam kehidupan siswa sehari-hari (Kilpatrick, 2001). Demikian pula, pada jenjang SD kelas 1-3, muatan Matematika selalu terintegrasi dengan muatan lain seperti IPA dan IPS. Oleh sebab itu, dalam Kurikulum 2013 dapat dinyatakan bahwa muatan Matematika memiliki kedudukan yang sentral dalam mengembangkan kecakapan matematis dalam kehidupan siswa.

Menurut Muhammad (2017:117) menyatakan bahwa kemampuan siswa dalam memahami sebuah konsep matematika masih rendah. Hal ini dibuktikan melalui beberapa indikator kecakapan pemahaman siswa pada aspek (1) menafsirkan terutama pada materi bangun datar, bangun ruang; (2) memberikan contoh bendabenda yang termasuk bangun ruang dan bangun datar; (3) mengklasifikasikan benda berdasarkan bentuknya (Suparman, 2012:138). Kurangnya contoh-contoh riil dan kontekstual dalam pembelajaran merupakan salah satu faktornya. Sementara, menurut beberapa guru, beberapa faktor penghambat proses pembelajaran meliputi: (1) proses pembelajaran tidak didukung oleh panduan yang jelas, (2) guru memberikan materi pembelajaran, tanpa bahan ajar yang dapat menarik perhatian siswa untuk belajar mandiri, dan (3) kurangnya sumber ilmu, fasilitas, dan waktu membuat siswa tidak aktif dalam proses pembelajaran (Jati, 2014:9).

Kementerian Pendidikan dan Kebudayaan No. 68 Tahun 2013 mendukung pola pembelajaran inovatif dan kontekstual. Sehingga diharapkan proses pembelajaran menjadi interaktif, menyenangkan, memotivasi, menantang, serta meninggalkan pola pembelajaran tunggal menjadi pembelajaran yang berpola multidicipline. Adanya kondisi tersebut memberikan benang merah bahwa sudah semestinya ada suatu upaya meningkatkan kemampuan matematika siswa dengan berbagai alternatif dan inovasi. Salah satu kuncinya adalah perbaikan proses pembelajaran, khususnya dengan meningkatkan porsi menalar, memecahkan masalah, berargumentasi dan berkomunikasi melalui pembelajaran yang lebih kontekstual. Pembelajaran matematika yang inovatif dapat dilakukan melalui media pembelajaran yang berbasis pendekatan budaya atau yang disebut etnomatematika.

Menurut Shirley (Marsigit, 2016) sekarang ini bidang etnomatematika, yaitu matematika yang tumbuh dan berkembang dalam masyarakat dan sesuai dengan kebudayaan setempat, dapat digunakan sebagai pusat proses pembelajaran dan metode pengajaran, walaupun masih relative baru dalam dunia pendidikan. Etnomatematika membutuhkan interpretasi yang dinamis. Sebagaimana dikemukakan oleh D'Ambrosio (2006) bahwa "The term requires a dynamic interpretation because it describes concepts that are themselves neither rigid nor singular-namely, ethno and mathematics".

Maka dapat diambil kesimpulan bahwa etnomatematika dapat dikatakan sebagai cara-cara khusus yang dilakukan oleh suatu kelompok tertentu dalam melakukan aktifitas matematika. Aktivitas matematika yang dimaksud adalah aktivitas yang di dalamnya terjadi proses pengabstraksian dari pengalaman nyata dalam kehidupan sehari-hari ke dalam matematika atau sebaliknya, meliputi aktivitas mengelompokkan, berhitung, mengukur, merancang bangunan atau alat, membuat pola, membilang, menentukan lokasi, bermain, menjelaskan, dan sebagainya. Sedangkan bentuk dari etnomatematika adalah berbagai hasil dari aktivitas matematika yang dimiliki atau berkembang pada kelompok itu sendiri, meliputi konsep matematika pada peninggalan 
budaya yang sangat popular adalah peninggalan nenek moyang kita yaitu candi Borobudur, Candi Prambanan dan Keraton Yogyakarta

Bahan ajar matematika berbasis etnomatematika yang akan digunakan dalam proses pembelajaran haruslah menarik dan dapat membuat siswa menjadi bergairah dalam belajar. Hal ini dimaksudkan untuk membentuk pola pemahaman pada materi dan konsep materi yang dipelajari melalui objek atau situs bersejarah. Materi pembelajaran dibuat berdasarkan literasi yang mudah dipahami oleh siswa berdasarkan materi matematika dan atau penerapan matematika yang telah membudaya dilingkungan masyarakat. Bahan ajar berperan sebagai sumber materi yang dapat membantu siswa belajar mandiri dan diharapkan siswa dapat memahami konsep dam materi bangun datar pada muatan matematika. Penggunaan bahan ajar matematika, analisis kelebihan dan analisis kekurangan bahan ajar yang digunakan nantinya menjadi bahan kajian dalam penelitian ini.

\section{METODE}

Pada penelitian ini kami menggunakan jenis/pendekatan penelitian yang berupa Studi Kepustakaan (Library Research). Menurut Mardalis Studi kepustakaan merupakan suatu studi yang digunakan dalam mengeumpulkan informasi dan data dengan bantuan berbagai macam material yang ada di perpustakaan seperti dokumen, buku, majalah, kisah-kisah sejarah, dsb (Mirzaqot, 2018). Adapun langkah-langkah dalam penelitian kepustakaan menurut Kuhlthau adalah sebagai berikut : 1. Pemilihan topik 2. Eksplorasi informasi 3. Menentukan fokus penelitian 4. Pengumpulan sumber data 5. Persiapan penyajian data 6. Penyusunan laporan (Muhammad, 2019). Teknik pengumpulan data dalam penelitian ini adalah dokumentasi, yaitu mencari data mengenai hal-hal atau variabel yang berupa catatan, buku, makalah atau artikel, jurnal dan sebagainya (Arikunto, 2010). Instrumen penelitian dalam penelitian ini adalah daftar check-list klasifikasi bahan penelitian, skema/peta penulisan dan format catatan penelitian. Teknik analisis data yang digunakan dalam penelitian ini adalah metode analisis isi (Content Analysis). Analisis ini digunakan untuk mendapatkan inferensi yang valid dan dapat diteliti ulang berdasarkan konteksnya. Dalam analisis ini akan dilakukan proses memilih, membandingkan, menggabungkan dan memilah berbagai pengertian hingga ditemukan yang relevan. Penggunaan bahan ajar matematika, analisis kelebihan dan kekurangan bahan ajar yang digunakan nantinya menjadi bahan kajian dalam penelitian ini.

\section{HASIL DAN PEMBAHASAN}

\section{A. Penggunaan Bahan Ajar}

Media pembelajaran merupakan peralatan yang digunakan dalam pengajaran sebagai suplemen dalam pengajaran di kelas untuk meningkatkan minat belajar siswa (Kumar, 2017). Bahan ajar adalah katalis penting untuk pengajaran yang efektif. Selain metode pengajaran konvensional, ada berbagai jenis media pembelajaran yang tersedia untuk guru. Media pembelajaran membantu siswa untuk meningkatkan keterampilan matematika dan lainnya.

Satu faktor penting tentang bahan ajar adalah bahan itu harus memenuhi kebutuhan siswa karena setiap siswa memiliki tingkat pemahaman sendiri. Seperti yang dikatakan Mauluah (2019), "Siswa perlu mempelajari materi yang berhubungan dengan dunia nyata dan harus secara positif terkait dengan aspek-aspek batin mereka seperti usia, tingkat pendidikan, sikap sosial, kemampuan intelektual dan tingkat kedewasaan emosional".

Media pembelajaran sangat penting untuk mempelajari matematika (Kumar, 2017). Media pembelajaran matematika mengembangkan gambar yang tepat dalam 
pikiran siswa dan menciptakan suasana yang menarik bagi siswa untuk membuat belajar semakin mudah dan jelas. Dalam hal ini, media pembelajaran dapat membantu meningkatkan kemampuan numerik, nalar, dan logika matematika siswa, sehingga guru dapat memberi pembelajaran dengan mudah dan menjelaskan konsep materi yang diajarkan.

Teaching Learning Materials made a shift from Response Strengthening to Knowledge Acquisition for construction of Knowledge (Mukherjee, 2017). Bahan ajar membuat perubahan dari penguatan respons ke akuisisi pengetahuan untuk konstruksi pengetahuan. Perubahan seperti ini sangatlah dibutuhkan oleh siswa dalam proses pembelajaran. Pengertian ini menggambarkan bahwa suatu bahan ajar hendaknya dirancang dan ditulis dengan kaidah instruksional karena akan digunakan oleh guru untuk membantu dan menunjang proses pembelajaran.

Teaching materials is a generic term used to describe the resources teachers use to deliver instruction (Stephney, 2016). Bahan ajar merupakan istilah umum yang digunakan untuk menggambarkan sumber daya yang digunakan guru untuk menyampaikan instruksi. Bahan ajar dapat mendukung pembelajaran siswa dan meningkatkan keberhasilan siswa. Idealnya, bahan ajar akan disesuaikan dengan konten penggunanya, untuk di kelas, maka digunakan oleh siswa dan guru. Bahan ajar datang dalam berbagai bentuk dan ukuran, tetapi semuanya memiliki kemampuan yang sama untuk mendukung pembelajaran siswa.

Teaching materials are the materials which the teacher can use to help students learn a mathematics through visual or audio perception (Simpson, 2019). Bahan ajar merupakan materi yang dapat digunakan guru untuk membantu siswa belajar matematika melalui persepsi visual atau audio. Siswa harus mampu berkontribusi untuk pencapaian tujuan praktis, budaya, dan pendidikan untuk belajar matematika. Bahan ajar yang baik akan sangat membantu memperkuat keinginan awal siswa untuk belajar matematika dan untuk mempertahankan antusiasme siswa selama pembelajaran berlangsung.

Dari beberapa pengertian diatas, maka dapat disimpulkan bahwa bahan ajar merupakan kumpulan materi dan gambar yang disusun oleh guru. Namun, istilah ini biasanya merujuk pada contoh konkret, seperti lembar kerja atau manipulatif (alat atau permainan pembelajaran yang dapat ditangani siswa untuk membantu siswa memperoleh dan mempraktikkan fasilitas dengan pengetahuan baru - misalnya. penghitungan dalam matematika, dll.).

Menurut Shirley (Marsigit, 2016) sekarang ini bidang etnomatematika, yaitu matematika yang tumbuh dan berkembang dalam masyarakat dan sesuai dengan kebudayaan setempat, dapat digunakan sebagai pusat proses pembelajaran dan metode pengajaran, walaupun masih relative baru dalam dunia pendidikan. Etnomatematika membutuhkan interpretasi yang dinamis. Sejalan dengan pendapat tersebut, (Tandililing, 2013) mengungkapkan bahwa etnomatematika adalah matematika yang diterapkan oleh kelompok budaya tertentu, kelompok buruh/petani, anak-anak dari masyarakat kelas tertentu, kelas-kelas profesional dan lain sebagainya. Didalam pembelajaran matematika di sekolah dasar (SD) dan matematika yang ditemukan siswa dalam kehidupan sehari- hari sangat berbeda. Oleh sebab itu pembelajaran matematika di sekolah dasar (SD) sangat perlu memberikan muatan antara matematika dalam dunia sehari-hari siswa yang berbasis pada budaya lokal dengan matematika sekolah.

Salah satu pembelajaran matematika yang inovatif di sekolah dasar (SD) dapat dilakukan melalui menyediakan bahan ajar berbasis budaya atau yang disebut etnomatematika. Bahan ajar berbasis Etnomatematika di sekolah dasar (SD) bisa didefinisikan sebagai bahan ajar khusus yang disusun oleh guru dalam melakukan aktifitas proses pembelajaran matematika di kelas sekolah dasar (SD) yang berkaitan dengan budaya, baik berupa bentuk atau kebiasaan yang sering ditemui oleh siswa. 
Salah satu bentuk dari bahan ajar berbasis etnomatematika yang dapat diadaptasi adalah berupa hasil perkembangan budaya pada suatu daerah.

\section{B. Kelebihan Bahan Ajar}

\section{Study From Anywhere, Anytime}

Hal terbaik tentang bahan ajar adalah siswa dapat mempelajarinya dari mana saja dan kapan saja. Tidak masalah di bagian negara tempat siswa tinggal, siswa dapat mengikuti kursus dan mulai belajar dimana saja. Siswa mendapatkan semua pengetahuan dan pelatihan di mana pun Anda berada di planet ini (Nagrale, 2013).

\section{No Commuting}

Nagrale (2013) menyatakan bahwa jika siswa memilih bahan ajar berbentuk cetak untuk belajar, maka siswa tidak harus mempunyai komputer di rumah atau di sekolah. Siswa hanya memerlukan niat dan konsesntrasi penuh pada proses pembelajaran. Seluruh informasi yang dibutuhkan pada materi yang akan dipelajari akan berada di genggaman siswa dan siswa tidak harus keluar kelas atau rumah dalam belajar.

\section{Flexibility to Choose}

Siswa harus mengikuti jadwal belajar yang ditetapkan sesuai dengan kurikulum sekolah. Tetapi siswa bisa mempelajari materi sesuai dengan kenyamanan siswa itu sendiri tanpa harus secara urut dalam mempelajari materi yang ada di bahan ajar. Bahkan jika siswa berada di luar kelas, proses pembelajaran jauh lebih dibebaskan dalam memilih materi tanpa terpaku pada kurikulum sekolah, sehingga manfaat bahan ajar adalah membuat siswa fleksibilitas untuk memilih materi belajar (Brown, 2017).

\section{Kekurangan Bahan Ajar}

\section{High Chances of Distraction In The Class}

Menurut Nagrale (2013) penggunaan bahan ajar berbentuk cetak adalah pilihan yang kurang tepat pada proses pembelajaran bila keadaan siswa (kelas) kurang kondusif. Hal ini dikarenakan bahan ajar berbentuk cetak memerlukan suasana yang nyaman dan tidak berisik pada saat proses pembelajaran agar siswa lebih mudah memahami dan mempelajari materi yang terdapat pada bahan ajar tersebut.

\section{No Social Interaction}

Siswa akan sering belajar sendiri sehingga mereka merasa terisolasi dan kehilangan interaksi fisik sosial pada saat diadakan diskusi di kelas atau di luar kelas. Selain itu, siswa tidak memiliki kesempatan untuk mempraktikkan pelajaran secara lisan (terlalu sering membaca). Kurangnya interaksi fisik dalam proses pendidikan dapat menyebabkan banyak masalah, seperti kurang pergaulan, berdiskusi dan merasa terisolasi (Dyrud, 2000).

\section{Takes A Lot of Time And Money}

Guru harus mengeluarkan banyak waktu dan uang dalam mempersiapkan bahan ajar berbentuk cetak (Brown, 2017). Guru akan kehilangan banyak waktu dalam proses penyusunan, pencarian materi, dan membuat bahan ajar agar lebih menarik perhatian siswa. Selain itu guru juga mengeluarkan banyak uang untuk mencetak dan mendistribusikan kepada siswa agar masing-masing siswa dapat meiliki bahan ajar ini satu persatu.

\section{SIMPULAN}

Pada hakekatnya, bahan ajar merupakan kumpulan materi dan gambar yang disusun oleh guru. Namun, istilah ini biasanya merujuk pada contoh konkret, seperti lembar kerja, alat atau permainan pembelajaran yang dapat digunakan siswa untuk membantu memperoleh dan mempraktikkan materi dengan pengalaman baru. 
Pembelajaran matematika di sekolah dasar (SD) sangat perlu memberikan muatan antara matematika dalam dunia sehari-hari siswa yang berbasis pada budaya lokal dengan matematika sekolah. Salah satu pembelajaran matematika yang inovatif di SD dapat dilakukan melalui mengaitkan materi dengan budaya atau disebut etnomatematika. Bahan ajar berbasis Etnomatematika di SD bisa didefinisikan sebagai kumpulan materi khusus yang disusun oleh guru dalam melakukan aktifitas proses pembelajaran matematika di kelas SD yang berkaitan dengan budaya, baik berupa bentuk atau kebiasaan yang sering ditemui oleh siswa. Kelebihan dari bahan ajar terdiri dari: 1) Study From Anywhere, Anytime; 2) No Commuting; 3) Flexibility to Choose. Sedangkan kekurangan dari bahan ajar terdiri dari: 1) High Chances of Distraction In The Class; 2) No Social Interaction; 3) Takes A Lot of Time And Money. Saran untuk pembaca yang lainnya adalah kreatif dalam menyusun bahan ajar sesuai dengan kemampuan siswa dan lingkungan, karena bahan ajar yang baik paling tidak memenuhi kebutuhan siswa yang memiliki tingkat pemahaman berbeda.

\section{DAFTAR PUSTAKA}

Arikunto, S. (2010). Prosedur Penelitian Suatu Pendekatan Praktik. Jakarta: Rineka Cipta

D'Ambrosio, U. (2006). Preface. Prosiding, International Congress of Mathematics Education Copenhagen. Pisa: University of Pisa.

Brown, C. (2017). Benefits of Teaching Learning Materials. Diakses dari https://www.eztalks.com/elearning/benefits-teaching-learning-materials.html.

Dyrud, M. A. (2000). The third wave: a position paper. Business Communication Quarterly, 63(3), 81-93. https://doi.org/10.1177/108056990006300310.

Kementrian Pendidikan dan Kebudayaan RI. (2013). Peraturan Mendiknas tentang Satuan Pengawasan Internal (Permendikbud No. 68 Tahun 2013). Jakarta: Kemendikbud.

Kementrian Pendidikan dan Kebudayaan RI. (2014). Peraturan Mendiknas tentang Satuan Pengawasan Internal (Permendikbud No. 57 Tahun 2014). Jakarta: Kemendikbud

Jati, Aufrida W.C. (2014). Faktor-Faktor Penghambat Proses Pembelajaran Biola Grade 1 Di Jogja Music School (JMS) Yogyakarta. Yogyakarta: Skripsi, UNY.

Kilpatrick, Swafford, dan Findell, (2001). Adding It Up: Helping Children Learn Mathematics. National Academy Press.

Kumar, Shravan. (2017). Teaching Material and Teaching Aids Paper 12 Module 24. India: V.S.S.D. College, University Kanpur.

Mauluah, Luluk. (2019). Ethnomatematics For Elementary Student: Exploration The Learning Resource At Kraton Yogyakarta. International Journal Of Scientific \& Technology Research , Vol. 8 Issue 07,. pp : 776-780, July 2019.

Marsigit. 2016. Pembelajaran Matematika Dalam Perspektif Kekinian. Math Didactic: Jurnal Pendidikan Matematika Vol. 2, No. 3, September - Desember 2016. STKIP PGRI Banjarmasin.

Mirzaqot, T.A. \& Budi Purwoko. (2018). Studi Kepustakaan Mengenai Landasan Teori Dan Praktik Konseling Expressive Writing. Jurnal BK UNESA Vol. 8 No. 1 Tahun 2018.

Mukherjee, T. (2017). Teaching Materials and Teaching Aids. Journal Phatashala Amity Univercity India No. 12 Vol. 24, Juli 2017. Hal. 3 -14.

Muhammad, Azamul F.N. (2017 a). Berpikir Profetik Dalam Pembelajaran Matematika SD/MI. Al-Bidayah: Jurnal Pendidikan Dasar Islam Vol. 9 No. 2, pp. 111-120.

Muhammad, Azamul F.N. (2019 b). Menumbuhkan Kedisiplinan Siswa Melalui Strategi Manajemen Intervensi. JPPSD (Jurnal Pemikiran dan Pengembangan Sekolah Dasar) Vol. 7 No. 1 April 2019. 
Nagrale, P. (2013). Advantages and disadvantages of distance education. Diakses dari https://surejob.in/advantages-anddisadvantages-of-learning-materials.html.

Simpson, A.P. (2019, Maret 2019). Teaching Aids and Teaching Materials in FLT. Diakses dari www.canvas.intructure.com.

Stephney, Shonette. (2016, June 2016). The Importance of Learning Materials in Teaching. Diakses dari www.education.gov.gy.com.

Suparman, Atwi. (2012). Desain Instruksional Modern. Jakarta: Erlangga.

Tandililing, E. (2013). Pengembangan Pembelajaran Matematika Sekolah Dengan Pendekatan Etnomatematika Berbasis Budaya Lokal Sebagai Upaya Untuk Meningkatkan Kualitas Pembelajaran Matematika Di Sekolah. Jurnal Prociding di Seminar Nasional Matematika dan Pendidikan Matematika 2013. FMIPA UNY. ISSN 978-979-16353-9-4. 